\title{
Designing biomimetic robots: iterative development of an integrated technology design curriculum
}

\author{
Debra Bernstein $^{1}$ (D) Gillian Puttick ${ }^{1} \cdot$ Kristen Wendell $^{2} \cdot$ Fayette Shaw $^{2}$. \\ Ethan Danahy ${ }^{2} \cdot$ Michael Cassidy ${ }^{1}$
}

Accepted: 22 October 2021 / Published online: 24 November 2021

(c) The Author(s) 2021

\begin{abstract}
In most middle schools, learning is segregated by discipline. Yet interdisciplinary approaches have been shown to cultivate creative thinking, support problem solving, and develop interest while supporting knowledge gains (NAE \& NRC in STEM Integration in K-12 Education: Status, Prospects, and an Agenda for Research. National Academies Press, Washington, 2014). The Designing Biomimetic Robots project emphasizes problembased learning to integrate engineering, science, and computational thinking (CT). During a 3 to 4-week unit, students study the natural world to learn how animals accomplish different tasks, then design a robot inspired by what they learned. The project engages students in science, engineering, and CT practices. Over the course of a 3-year project, we used a design-based research approach to: (1) identify and describe strategies and challenges that emerge from integrated curriculum design, (2) explicate how a balance of integrated disciplines can provide opportunities for student participation in science, engineering, and CT practices, and (3) explore how a technology design task can support students' participation in integrated learning. Data from three focal groups (one from each year of the project) suggest that a focused design task, supported by explicit and targeted supports for science, $\mathrm{CT}$, and engineering practices, led to a student technology design process that was driven by disciplinary understanding. This work highlights the importance of drawing out and prioritizing alignments between disciplines (Barber in Educ Des, 2(8), 2015), to enable integrated learning. Additionally, this work demonstrates how a technology design task can support student learning across disciplines, and how engaging in CT practices can further help students draw these connections.
\end{abstract}

Keywords Design-based research · Robotics · Integration · Biology $\cdot$ Engineering · Computational thinking

Debra Bernstein

debra_bernstein@terc.edu

1 TERC, 2067 Massachusetts Avenue, Cambridge, MA 02140, USA

2 Center for Engineering Education and Outreach, Tufts University, 200 Boston Avenue, Medford, MA 02155, USA 


\section{Introduction}

In most middle schools, learning is segregated by discipline-science in one class, and engineering or computing, if at all, in another. Yet recent trends in science and engineering education suggest this approach is outdated. Integrated approaches have been shown to cultivate creative thinking, support problem solving, and develop interest while supporting knowledge gains (NAE \& NRC, 2014).

The Designing Biomimetic Robots (BioRobots) project uses a design-based research (DBR) approach and emphasizes problem-based learning in an interdisciplinary integration of engineering, science, and computational thinking (CT). In a 3- to 4-week curriculum, students first study the natural world to learn how animals accomplish different tasks. Then, they engineer a robot that is inspired by what they learned. In the process, students engage in science practices (such as obtaining and evaluating information, constructing models), engineering practices (such as realizing designs, testing, and troubleshooting), and computational thinking practices (such as abstraction, decomposition, and algorithmic thinking), drawing on multiple disciplines while solving a design problem (Wendell et al., 2020). We have chosen to use robotics as a way to anchor students' interdisciplinary experience because robotics design tasks have been shown to support student learning in all three areas (see Anwar et al., 2019; Cuperman \& Verner, 2019; Souza \& Duarte, 2015; Sullivan \& Heffernan, 2016). The overarching goals of the BioRobots project are: to help develop understanding of how integrated curricular resources can support students' developing competence in science, engineering, and CT practices while creating a curriculum that can serve as a promising model for integrated design; and to understand the role robotics design tasks can play in supporting students' integrated learning.

DBR (Cobb et al., 2003; Collins et al., 2004) is particularly suited for this design challenge because it integrates iterative cycles of design with research about the ways in which processes contribute to and mediate outcomes (Easterday et al., 2014; McKenney \& Reeves, 2019; Sandoval, 2014). Furthermore, design studies can contribute to theory development in the fieldto understand better the conditions for bringing about particular learning outcomes - and also the development of usable innovations (Edelson, 2002; Sandoval, 2014).

This paper describes how the project team developed, tested, and refined an integrated curriculum (consisting of student and teacher materials, and technology supports) that utilized robotic technology to support student learning in science, engineering, and CT. In doing so, we reflect on the ways in which a technology design task can be used to support integrated STEM learning and contribute to the literature by demonstrating how a DBR process can be used to help enhance disciplinary integration. The paper addresses the following research questions:

- How can a technology design task support students' participation in integrated learning of practices related to biology, engineering design, and computational thinking (CT)?

- What challenges and strategies emerge while designing an integrated curriculum to support productive student use of three disciplines to solve a technology design task? 


\section{Theoretical framework}

The importance of making connections among STEM disciplines is underscored by an increasing recognition among educators and policy makers that STEM in the real world is often multi-disciplinary. Students who can work flexibly in multiple disciplines will be better prepared for this reality (Margot \& Kettler, 2019; NAE \& NRC, 2014). The field has seen an uptake in instructional approaches that reach across STEM disciplines (see, for example, Walker et al., 2018). Research on the design, enactment, and outcomes from interdisciplinary curricula underscore the importance of this approach. However, the literature provides only limited guidance on how to think about technology-enhanced curriculum development in this area.

\section{Defining integrated STEM}

In recent years, there has been a proliferation of curriculum projects integrating multiple disciplines, both within STEM (Lee \& Malyn-Smith, 2020; NAE \& NRC, 2014), and between STEM and non-STEM disciplines (e.g., Barber, 2015). The research literature uses a number of different terms to describe the spectrum of curricular integration. Huntley (1998) defines three terms that describe this spectrum: intradisciplinary, focusing on one discipline; interdisciplinary, focusing on one discipline but with a supportive secondary discipline providing context or relevance; and integrated, "a synergistic union of the two disciplines, the result being an activity or curricular unit in which the interactions between the disciplines result in students learning more than just the [content of individual disciplines] contained therein" (p. 322). Building on the work of Huntley and others, Stoddart et al. (2002) use the terms 'thematic,' 'interdisciplinary', and 'integrated', while Nadelson and Seifert (2017) describe 'Integrated STEM' as the "seamless amalgamation of content and concepts from multiple STEM disciplines... [where] knowledge and process of the specific STEM disciplines are considered simultaneously without regard to the discipline, but rather in the context of a problem, project, or task" (p. 221). We view the latter definition as most relevant to the current work, in which we sought to create an integrated learning experience for students which drew from three disciplines-biology, engineering, and robotics.

\section{Designing and enacting integrated STEM}

Designing for integrated learning is challenging and requires continuous efforts towards recognizing natural synergies between disciplines (Barber, 2015). Those synergies can be sought during the design phase, by identifying how the integrated discipline is already present in existing activities and/or where it can be extended by developing new integrated lessons (Waterman et al., 2020). For example, English and Mousoulides (2015) extended an engineering design task to create a transdisciplinary STEM curriculum by adding mathematical modeling activities to an engineering curriculum (English, 2016). Design sequences that explicitly emphasize making connections among ideas from different sources (e.g., Knowledge Integration instructional pattern; Chiu \& Linn, 2011) can also be useful in helping students connect across disciplines, as can designing evaluation criteria (e.g., grading rubrics) that emphasize disciplinary integration in student work products.

During enactment, teachers can support cohesion across STEM disciplines by paying explicit attention to how activities and representations connect to one another (Nathan 
et al., 2013). Integrated curricula need to provide supports for teachers to use strategies such as identification (of consistent relationships and representations), forward/backward projection (references to representations or activities in the past or future), and coordination (linking materials or representations), to support student understanding (Nathan et al., 2013).

Integrated curricula often allow students and teachers to engage higher-order thinking skills (Nadelson \& Seifert, 2017). When studying classrooms along the continuum of interdisciplinarity, Applebee et al. (2007) found that classrooms enacting more integrated curricula tended to use more 'cognitively engaging instruction' (i.e., activities that emphasized meaning-making such as asking questions, developing hunches, and elaborating on ideas) than classrooms that were more discipline-based.

\section{Learning outcomes}

Integrated learning environments are often associated with positive student learning outcomes such as creative thinking, support problem solving, interest development, and knowledge gains (NAE \& NRC, 2014). Hurley's (2001) meta-analysis of 31 studies of integrated math and science curricula found evidence to support integrated learning in K-12, while Becker and Park (2011) found K-12 student gains in integrated STEM instruction, including those that integrated technology and science. Other studies show positive gains for science content knowledge in an integrated science and engineering elementary school curriculum (Wendell \& Kolodner, 2014; Wendell \& Rogers, 2013), and gains on both physical science and computational thinking assessments during an integrated physics and CT unit (Aksit \& Wiebe, 2019). Integrated approaches can also positively impact students' attitudes and interest development (Michelsen \& Sriraman, 2009). For example, students showed positive engagement and science identity construction in an integrated science and literacy curriculum (Tucker-Raymond et al., 2013).

Aksit and Wiebe (2019) describe an activity that integrates physics and computational thinking (CT) by having students model force and motion concepts using Scratch (a drag and drop programming application). Their research demonstrates how developing algorithms (CT) directly supports students' understanding of force and motion (physics), because, "students needed to conceptually understand what is meant by acceleration and how the velocity of the object is related to and calculated from its acceleration" in order to complete their program (p. 74). Similarly, (Puttick \& Tucker-Raymond, 2018) have shown that designing games in Scratch about climate change has supported student understanding of climate systems complexity by emphasizing similarities in game systems and natural systems.

\section{Robotics design to support student learning}

Robots are becoming increasingly common in K-12 education (Benitti, 2012). Educational interventions that include activities such as designing, building, and programming robots have been shown to promote critical thinking skills (Atmatzidou \& Demetriadis, 2016; Bers et al., 2014; Sullivan, 2008), understanding of complex systems (Barker \& Ansorge, 2007; Sullivan, 2008), self-efficacy (Nugent et al., 2010) and positive attitudes towards science (Welch \& Huffman, 2010). When students design and build robots, they create design representations (e.g., sketches and other tangible prototypes), collect feedback and iterate on their designs, engage in critique of their own and others' work (Gomez et al., 2012), and 
practice teamwork and collaboration (Gomez et al., 2012; Nourbakhsh et al., 2005). Programming, an important part of robotics work, engages students in computational thinking practices such as problem decomposition and algorithmic thinking (Grover \& Pea, 2013). A $r$ review of the educational robotics literature suggests that working with robotics construction kits supports learning progressions in computational thinking (Sullivan \& Heffernan, 2016).

Integrating robotics into disciplinary classrooms can also support learning goals in other disciplines (Benitti, 2012; Hamner et al., 2016). Initial evidence suggests that engaging in robotics design activities (including designing, building, and programming) may contribute to learning in biology (Cuperman \& Verner, 2013), physical science (Mitnik et al., 2009), mathematics (Saez-Lopez et al., 2019), and engineering (Cejka et al., 2006). In the biological sciences, for example, Cuperman and Verner $(2013,2019)$ found that students recognized the ways in which a robot they designed did (and did not) align with their disciplinary understanding of a biological system, and used that knowledge to prompt a re-design of their robotics mechanism to improve alignment between and build deeper understanding of robotic and biological structures and functions.

\section{Methods}

This project adopted a DBR approach, enabling us to examine our conjectures about "processes the intended design will engender" (McKenney \& Reeves, 2019), as they related to our research goals, and to analyze changes over the course of the project. In line with the DBR approach, emerging findings each year caused a shift in our research focus in each subsequent year of the project.

\section{Educational intervention: an evolving design}

Our overarching goal in the BioRobots curriculum is to create an integrated learning environment for students in which the robots they design represent an understanding of structure-function relationships in both engineering and biological contexts. Our curriculum design sought to honor our overarching design conjecture (Sandoval, 2014) that studying biological organisms will support student understanding of structure-function relationships. Using this understanding to design a robot will support student practices in engineering design and computational thinking $(C T)$. Conjectured embodiments and mediating processes follow from this conjecture (McKenney \& Reeves, 2019) (Fig. 1).

At the start of the unit, students are presented with the design challenge of creating biomimetic robots that can perform in a search-and-rescue environment. This design challenge requires students to create a conceptual model of the animal structure-function relationship by decomposing the animal system (Buckley, 2000), extracting relevant principles to create their model (Clement \& Rea-Ramirez, 2008), then using the model as a basis for conceptualizing their robot design, and building a functional robot. The design and programming tasks engage students in CT practices such as decomposition, abstraction, iteration, debugging and algorithmic thinking (Gomez et al., 2012; Grover \& Pea, 2013).

The curriculum provides resources to support investigations in biology (text, curated videos about animal structures and functions) and engineering (examples of mechanisms to build into robot designs, design worksheets to support student design processes). Students 


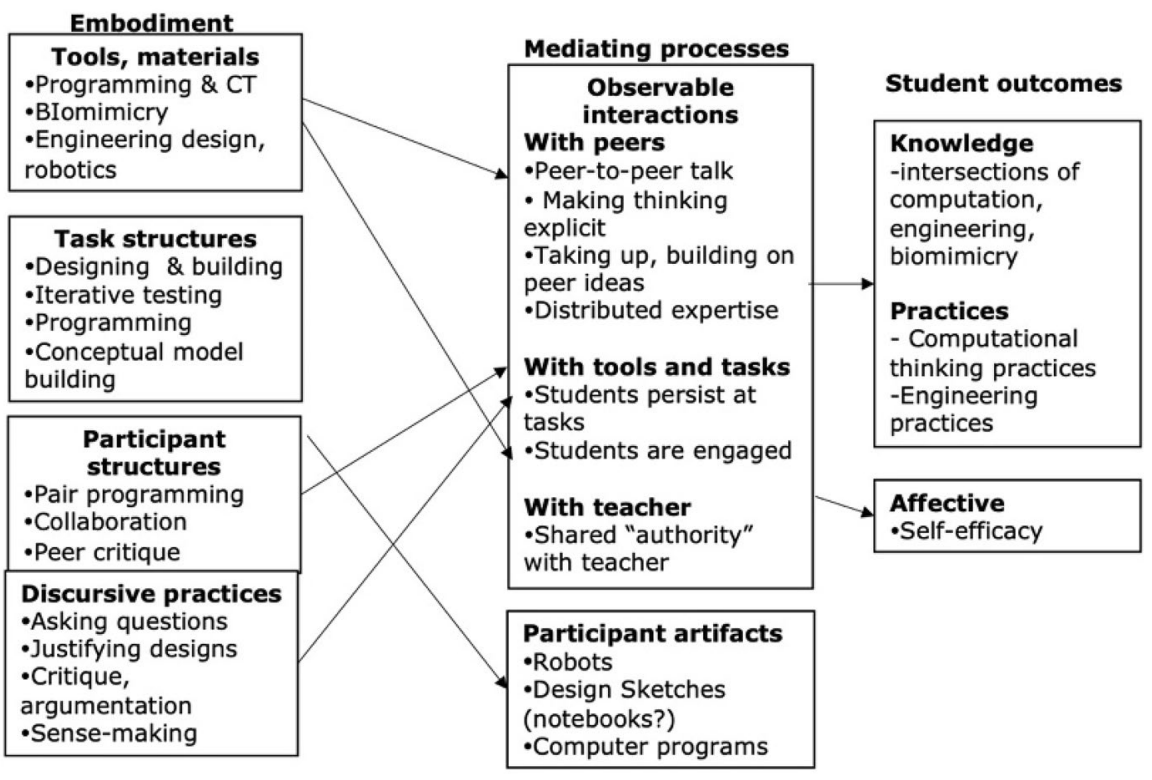

Fig. 1 Initial design conjectures

then build robots using craft materials and the Hummingbird classroom robotics kit (microprocessor, motors, and lights), and program robots in Scratch or MakeCode.

Our instructional approach to the student design task, and the ways in which we have sought to support students in practicing engineering design, biological investigations, and CT, have changed over the course of the project. The current paper examines the tensions inherent in designing a truly integrated curriculum by describing our design iterations and presenting data from the student experience across the 3 years of the project.

\section{Year 1}

The focus for our research in Y1 was to examine the extent to which the scope of the design task impacted student participation in practices related to engineering design, computational thinking (CT), and biology.

In the first year, each student group designed a biomimetic search and rescue robot that could address a challenge of their choice in any one of four natural disasters (fire, tornado, earthquake, hurricane), as well as designing the robot testing scenario (Shaw et al., 2018). While this allowed for a wide range of possible solutions among groups, each student group was designing a robot to perform a different task. To address the curriculum learning goals in biology related to animal structure and function (see Table 1), students were provided with resources to study a variety of animal actions (digging, moving through difficult terrain, grasp/carry objects, break objects, sense/find objects). Furthermore, the curriculum resources cued students to frame the experience as one primarily of engineering design (ED), for example by including several worksheets that addressed early phases of ED related to the learning goals of defining criteria and constraints appropriate to the given design challenge, and specifying actions and movements for the robot to perform, among others (Table 1). Programming the robots via a drag-and-drop programming language 


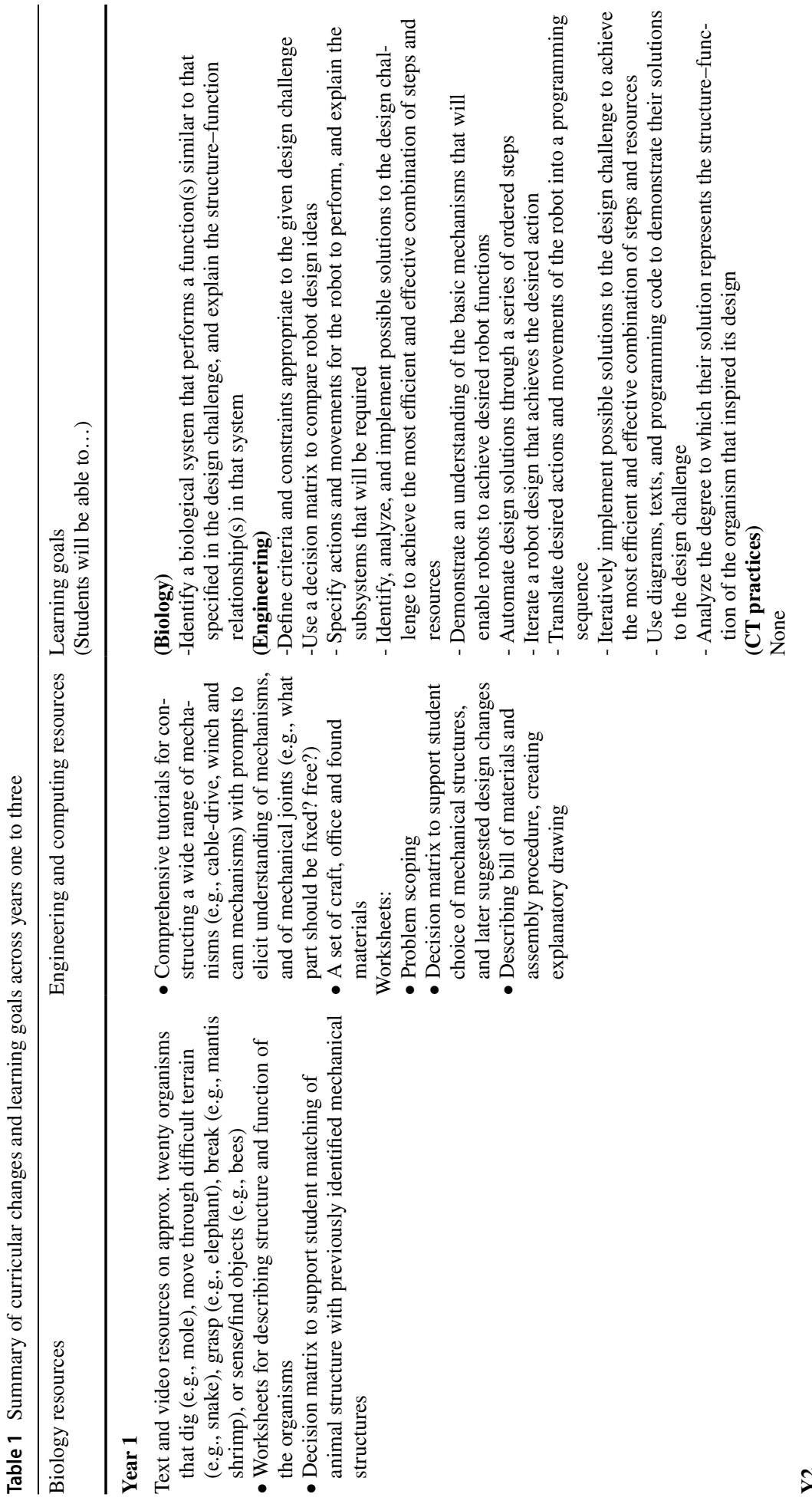




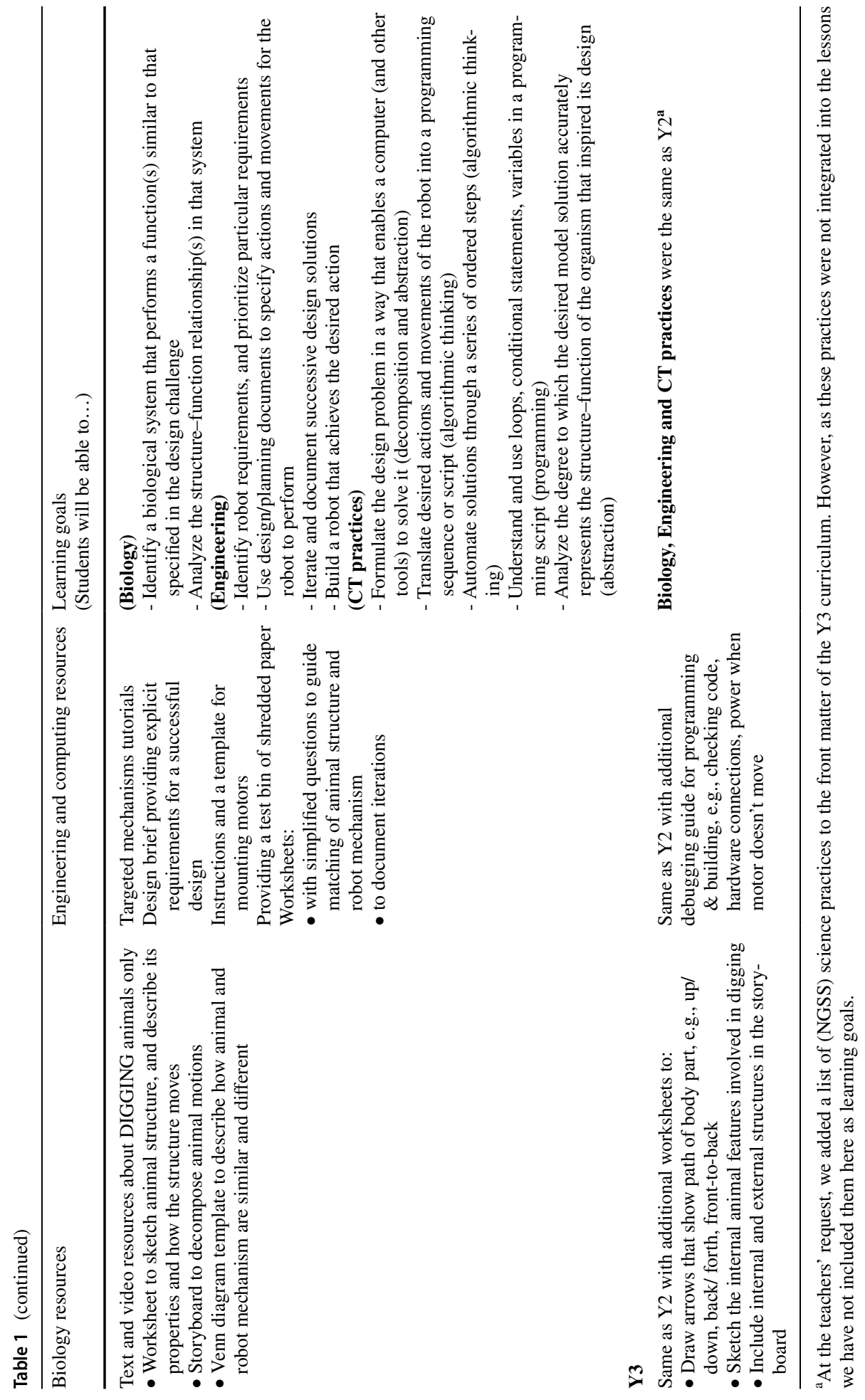


was supported through the provision of print tutorials and online video demonstrations. Although CT goals were intended and stated in the curriculum front matter they were not explicitly supported in the student and teacher materials.

\section{Year 2}

The focus of our research in Y2 was to examine the impact of stronger supports for science and engineering practices in helping students to engage in a more discipline-driven technology design process. In addition, we turned our attention to computational thinking practices by exploring ways in which they overlapped with practices in the other disciplines.

The revised curriculum presented a narrowly defined design task-students were asked to design a robot that could dig in earthquake rubble, and to test it in a bin filled with shredded paper. This task did not require a mobile robot (the robot could be stationary with digging appendages), which focused students' efforts on the elements of the robot that were biomimetic with respect to animal structures and functions used in digging. The narrowed scope of the design task allowed the design team to provide a more targeted set of biology resources for students and teachers, which focused solely on digging animals. The resources highlight four animals well adapted to digging: pangolins (hook-and-pull diggers), gophers (scratch diggers), mole rats (chisel-teeth diggers), and moles (humeralrotation diggers), and readings about the animals included details of skeletal and muscular adaptations for digging.

The increased focus on biology in support of a more even balance of the two disciplines necessitated a streamlining of the ED features of the curriculum to keep its overall duration from becoming unwieldy. This resulted in a reduction in the number of engineering learning goals, for example, a focus on problem scoping was no longer necessary with the new design task. The decision matrices to weigh the relative merit of different ideas both for robot function and for robot design were also removed to reduce data documentation.

Midway through $\mathrm{Y} 2$, in response to a request from a participating teacher for more explicit clarity regarding how CT practices aligned with the other disciplinary practices, the project team added a diagram to the teacher guide which specified the engineering design practices, science practices and CT practices engaged during each of the four curriculum modules. We also further emphasized students' CT practices during all activities (not just programming). For example, thinking of the sequence of activities related to animal structure-function analysis as decomposition and abstraction, we created additional worksheets and templates that allowed students to decompose animal structures and functions, abstract and represent a sequence of animal movements, and consider the similarities and differences between animal and robot structure-function. Specifically, students were asked to complete a storyboard of 3 labelled sketches (abstraction) to show digging at several points of time, and also to explicitly compare and contrast animal and robot structure-function.

Additional changes to support students' ED included a more limited number of mechanisms in the mechanism tutorial set, as well as supportive templates, for example, providing detailed instructions for mounting motors, providing an opportunity (via pre-programmed motors) for students to observe the range and types of motion prior to designing their robots, and a "change log" with prompts to better support documentation during design iteration. Programming support was provided via a 'test your understanding' activity where students drew connections between a written and displayed program. 


\begin{tabular}{|l|}
\multicolumn{1}{|c|}{ Embodiment } \\
Tools, materials \\
-Programming \\
- Computational \\
thinking \\
(decomposition, \\
abstraction, \\
algebraic thinking, \\
iteration) \\
-BIomimicry \\
-Engineering design, \\
robotics \\
\hline
\end{tabular}

\section{Student outcomes}

\section{Knowledge}

-intersections of

computation, engineering,

biology

Practices (CT and ED)

- Decomposition of

animal and robot

- Abstraction/modeling

- Algorithmic thinking

- Collaboration

- Iteration

Fig. 2 Y3 revised design conjectures

\section{Year 3}

Our research focus in Y3 was to examine the extent to which additional supports around structure-function analysis, in biology, engineering and CT, deepened the integration of disciplinary understanding into the student design process.

In intensive work sessions over the summer, we examined the alignment between student work and our intended learning goals, and also consulted extensively with teachers. These activities resulted in a revised conjecture map that reflected our evolving thinking about the alignment of science, engineering and CT practices (Fig. 2).

Refinements in the third year of the project focused on further strengthening support for structure-function analyses, much of which was spurred by our deepening thinking about the correspondence between $\mathrm{CT}$ practices, science practices and engineering practice. For example, students were now explicitly asked to include internal structures (e.g., bones and muscles) in their sketches of the motion storyboard and to include vector arrows indicating direction or path of motion of digging appendage in both their animal and robot sketches, both tasks designed to strengthen deeper application of their biology, ED and CT practices. In addition, a new worksheet was designed specifically to support student abstraction from their analysis of the structure-function relationship in the animal to a robot mechanism that "mimicked" the animal. Prompts were also provided for teachers to facilitate classwide conversations about comparative anatomy so as to draw student attention to digging adaptations such as short stout bones, enlarged muscle attachments, etc., and to relate these explicitly to robot designs.

Table 1 summarizes the main design features of the curriculum and our design iterations across the 3 years of the project.

\section{Participants}

Each year, the BioRobots curriculum was implemented in science classes, engineering classes, enrichment blocks, and after-school programs in urban, suburban, and rural school districts. A total of 21 teachers participated in the project over 3 years, including engineering teachers $(n=5)$, science teachers $(n=11)$, engineering and science teachers $(n=2)$, and teachers of math and technology $(n=3)$. See Table 2 for participation across the study as a whole. 
Table 2 Student and teacher participants across the 3-year BioRobots research study

\begin{tabular}{lccc}
\hline Year & $\begin{array}{l}\text { Total number of } \\
\text { teachers* }\end{array}$ & $\begin{array}{l}\text { Total number of } \\
\text { students }\end{array}$ & $\begin{array}{l}\text { Total number } \\
\text { of implementa- } \\
\text { tions* }\end{array}$ \\
\hline Y1 & 4 & 58 & 3 \\
Y2 & 9 & 300 & 8 \\
Y3 & 15 & 440 & 12
\end{tabular}

*Some teachers co-taught the BioRobots curriculum unit, leading to a different number of teachers and classroom implementations. Some teachers participated in the project for multiple years

Table 3 Characteristics of focal groups described in the results section, by study year

\begin{tabular}{lllll}
\hline Year & School district & Classroom type & Grade & $\begin{array}{l}\text { \# of students } \\
\text { in focal } \\
\text { group }\end{array}$ \\
\hline Y1 & Urban & Engineering and technology & 7th and 8th & 4 \\
Y2 & Rural & Enrichment block & 7th and 8th & 3 \\
Y3 & Rural & Enrichment block & 7th and 8th & 2 \\
\hline
\end{tabular}

During Y1 and Y2, researchers visited all classroom sites each day while the BioRobots project was running. During Y3, researchers visited five classroom sites daily during implementation. The Y3 case study was drawn from one of these sites. Students worked in groups of 2-4 to design and build robots. At each fully visited site, researchers chose two groups of students as the focus for audio/video recording and field notes (hereby referred to as "focal groups"). These focal groups were chosen in consultation with the classroom teacher, according to the following criteria: (1) full consent to participate in the research study; (2) high likelihood of consistent attendance; (3) high likelihood of conversation. In some classrooms focal groups included high performing students, but this was not a selection criteria and therefore not consistent across sites.

We have selected three focal groups (one from each year; see Table 3) to demonstrate what the curriculum 'looked like' during different stages of design and development, and to describe the extent to which student activities during implementation aligned with the curriculum's learning goals. As in all design-based curriculum implementations, a range of artifacts was produced by students in response to the curriculum materials. In selecting groups to highlight in this paper, we have purposely chosen groups from classrooms where the student artifacts represented an understanding of the design task as presented and supported by that year's curriculum.

The Y1 implementation classroom was a 7th/8th grade technology class in an urban school district (Table 3). The class was taught by an engineering teacher. The Y2 implementation classroom was a 7 th/8th grade elective enrichment block (designated to provide students with additional learning opportunities) in a rural school district. The class was co-taught by two science teachers. The Y3 implementation classroom was an enrichment block in the same school district as the Y2 classroom, co-taught by the same teachers. All three implementations ran for approximately 20 class sessions, lasting between 45 and 60 min each. 


\section{Data sources}

Data collected from focal student groups included:

- Classroom observations and field notes, guided by an observation protocol designed by the research team to focus on use of materials, tools, and resources (by students and teachers), student-student and student-teacher interactions around focal concepts, and student participation in engineering design, CT, and biology practices.

- Student group interviews, guided by an artifact interview protocol (Brennan \& Resnick, 2012) designed by the research team to focus on robot design process and product and biomimetic robot elements, were conducted at the end of the curriculum implementation. Interviews lasted between 15 and $30 \mathrm{~min}$.

- Student artifacts, including biology worksheets, engineering design documentation, robot programs.

- Completed student robots, as documented in photos and video.

\section{Analysis}

As part of the DBR process, the project team reviewed data each year to understand the range of curriculum enactment across participating classrooms (e.g., Sandoval, 2014). Additionally, we developed case studies (Yin, 2009) for one focal group each year, that describe students' curriculum participation in greater depth. In choosing the case study each year, we focused on groups whose work exemplified the integrated disciplines most fully. Case study analysis focused on (1) student participation in each of the curriculum's primary disciplines (biology, engineering, robotics), and (2) student use of the CT skills supported by the curriculum (decomposition, abstraction, iteration, algorithmic thinking). All available data sources were examined for case study analysis. Written data sources (transcribed interviews, artifacts, and field notes) were coded according to an open coding scheme (Corbin \& Strauss, 2015) informed by the curriculum learning goals. For example, codes within the 'Biology' heading included animal decomposition, structures, functions, abstraction of animal movement. Codes within the 'Engineering' heading included iterative robot design, and relationship between animal structure-function and robot design. Codes within the 'Robotics' heading included technology and programming. Completed robots were analyzed for the degree to which they embodied biological structures and functions as the basis for mechanical structures and functions. Data for each case were examined in a pre-determined order: artifacts, interviews, then field notes. The first two authors coded each data set independently.

Coded data were then compiled into narratives depicting the design process for each focal group, and discussed by members of the research team. Disagreements between coders were resolved via consensus. Next, narratives were analyzed in light of alignment with the curriculum's stated learning goals (see Table 1).

\section{Results}

The data below describe the extent to which students' participation in BioRobots activities aligned with the curriculum's learning goals. In the following section, we summarize the challenges encountered and strategies used to support STEM integration during the design task. 


\section{Year 1}

During Y1 the open-ended nature of the design task led to a wide range of implementation outcomes. In all three classrooms, there were some focal groups that did not complete the design task and others whose robots did not integrate biology (e.g., designing a robotic car).

For the current analysis, we have chosen to highlight a Y1 focal group that, with support from their classroom teacher, remained true to the biomimetic goal of the curriculum. This focal group was atypical for Y1 in that their teacher actively supported students to make connections between their focal animal and their robot design, even though the project's Y1 curriculum materials did not adequately support those connections. In the excerpts below, we highlight the ways in which the teacher supported student thinking. These supports were later added to the Y2 curriculum.

\section{Design goal}

The goal that the ScoutRoach group identified for its robot was to fit through small spaces. Their animal inspiration was the cockroach.

\section{Biology goal: understanding structure-function relationships}

Field notes documented that Miles, inspired by a cockroach-like toy he saw online, googled "robotic bugs," while Devan explored information about cockroaches alongside him. The group was taken by the cockroach's ability to compress its body, noting in their design documents that "cockroaches can squeeze through a crevice as small as a quarter of their body weight. Only the tightest space can slow them down." Among the project resources was a video that demonstrated the cockroach's ability to change its body shape. Toggling among these images, the group agreed to build the ScoutRoach, reading online that the cockroach toy showed "passive sprawling when vertically compressed." As one group member explained in an interview, "when it's about to get squished, it bends its legs, then when it's done it comes back up." Besides the legs, group members also recognized that the cockroach's body could flatten when needed, and then reform to its regular size and shape. In line with the curriculum's learning goals, the group identified the functions involved in the cockroach compressing its body. However, they did not fully identify the structures that allowed this to happen (e.g., jointed legs).

\section{Engineering design goals: enacting the engineering design process}

Students needed targeted teacher support to meet the curriculum's engineering design goals. Field notes documented that the teacher helped the group prioritize certain actions for the robot, and encouraged them to try out and evaluate different designs for the robot's legs, thereby supporting the ED practice of iteration. The group ultimately designed a robot that accomplished the same function as the cockroach — changing its size-but using a different mechanism than the actual animal.

Most of the group's iterative work focused on designing legs that could lengthen and compress, and designing a mechanism to move the robot's body up and down. In the first iteration the legs consisted of plastic straws segmented and braced internally with skewers, 


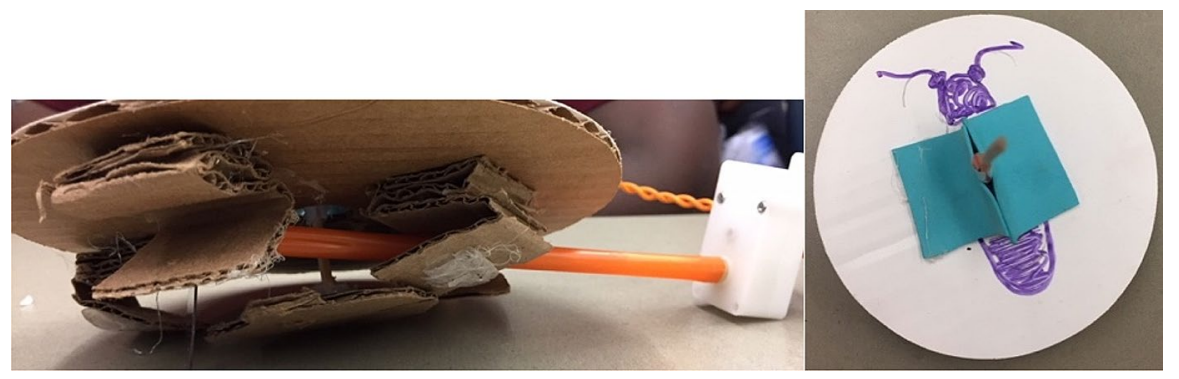

Fig. 3 Scoutroach side (left) and top view (right) inspired by a cockroach. The robot's legs passively accordion up and down, although the robot itself moves vertically via a cam mechanism (attached to the orange straw). (OTERC 2021

but actuating them to bend proved to be difficult. The final accordion design (for passive compression of the legs) and cam design (for moving the body up and down) were drawn from an example of possible mechanism designs in the curriculum. The teacher provided suggestions for many of the group's iterative designs (Fig. 3). The focal group students were unsure how to program the robot, so another student in the class created the program for them.

In analyzing this group's work, it became clear to the design team that while the curriculum's engineering design goals were perhaps appropriate for a single-discipline curriculum, they were too extensive for an integrated project. This encouraged the group to carefully evaluate which engineering design goals were critical to support rigorous and rich student work.

\section{Computational thinking goals}

As mentioned above, elements of CT practices were articulated in the front matter of the curriculum, but were not explicitly described and integrated in the Y1 curriculum itself. (As a result, we have not discussed the Y1 student work in terms of CT practices.) As described earlier, this prompted the design team to interrogate the curriculum specifically through a computational thinking lens when redesigning for $\mathrm{Y} 2$.

\section{Next steps}

While the Y1 curriculum introduced the idea of biomimicry, the intended goal of helping students use animal structure-function relationships to inform robot design was only partially met. This group needed help from their teacher to focus their robot design efforts.

The broad scope of the design challenge made it difficult for teachers to consistently support students in modeling biological relationships in their technology design. It also posed difficulties for the curriculum design team in selecting what resources to develop to support the range of biomimetic solutions that students desired. The Y2 curriculum narrowed the scope of the design task by specifying that students design a digging robot, and providing detailed resources about four animals that are well-adapted for digging. Additionally, the Y2 curriculum materials provided explicit student instruction on how to analyze an animal's structures and functions, presented students with a narrower range of potential engineering mechanisms, and included additional design documentation 
to support productive design iteration that considered the similarities/differences between the animal and robot structures and functions. These additions were meant to reduce the scope of the design problem, while supporting students in what we were coming to see as two key CT practices-decomposition and abstraction-and helping to make students' design iterations more productive. The Y2 curriculum thus included specific CT goals and re-imagined activities to strengthen the integration of these practices into biology and engineering design work.

\section{Year 2}

During Y2, each of the focal groups completed an animal structure-function analysis, and designed a robot based upon one of the four digging animals presented in the curriculum (mole, mole rat, pangolin, pocket gopher). The highlighted focal group was fairly typical for $\mathrm{Y} 2$ in that they were able to draw connections between their animal and robot design at the outset, but was atypical for $\mathrm{Y} 2$ in that they tried to maintain their biomimetic stance in their later design iterations.

\section{Design goal}

The design goal, to build a robot that could dig through rubble at a disaster site, was provided by the curriculum. The animal inspiration for the group presented here was the pangolin.

\section{Biology goal: understanding the structure-function relationship}

Students began by using resources provided by the project (videos and written text) to conduct an analysis of the structures and functions their target animal used for digging. In their final written documentation, the team identified four structures and functions that help pangolins dig: "hands (to scoop dirt and/or push dirt away), claws (to scrape at rocks and dirt, move things out of the way), head (to sense where the food is), and nose (pushes dirt back to secure access to food)". Students were then able to abstract the motion of the pangolin's arm into three main steps: the pangolin extends its arm, curves its hand to scoop the dirt up with palm and claws, then pulls the dirt back out of the hole (Fig. 4). This representation of pangolin motion highlighted both the parts involved in helping a pangolin dig, and the sequence of motions that it undertakes to dig. The group's identification of pangolin adaptations for digging was consistent with the curriculum's biology learning goals, and was more detailed than the analysis completed by the year 1 students.

\section{Engineering design goals: enacting the engineering design process}

Building directly on their abstraction of the pangolin's digging motion, the team proposed using a cable-drive mechanism to bend the pangolin's hand, so that the robot could scoop debris in the same way as the pangolin (see Fig. 5). The cable-drive mechanism was drawn from the building tutorials provided in the curriculum materials.

In their design documentation, the group indicated that their robot's "arm bends and the claw pulls back the dirt and also grabs rocks" and that they "got the digging motion... it digs the same as our animal." Consistent with the curriculum's engineering 

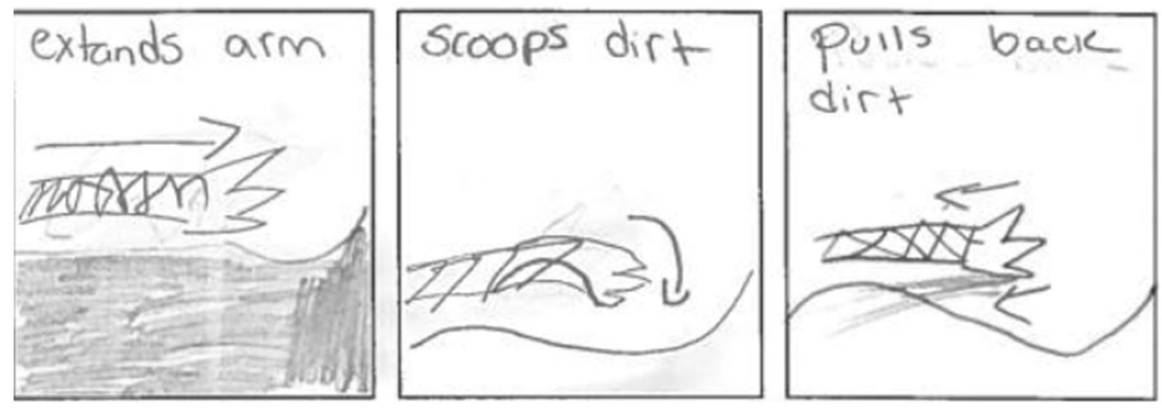

Fig. 4 Storyboard of pangolin movement. CTERC 2021

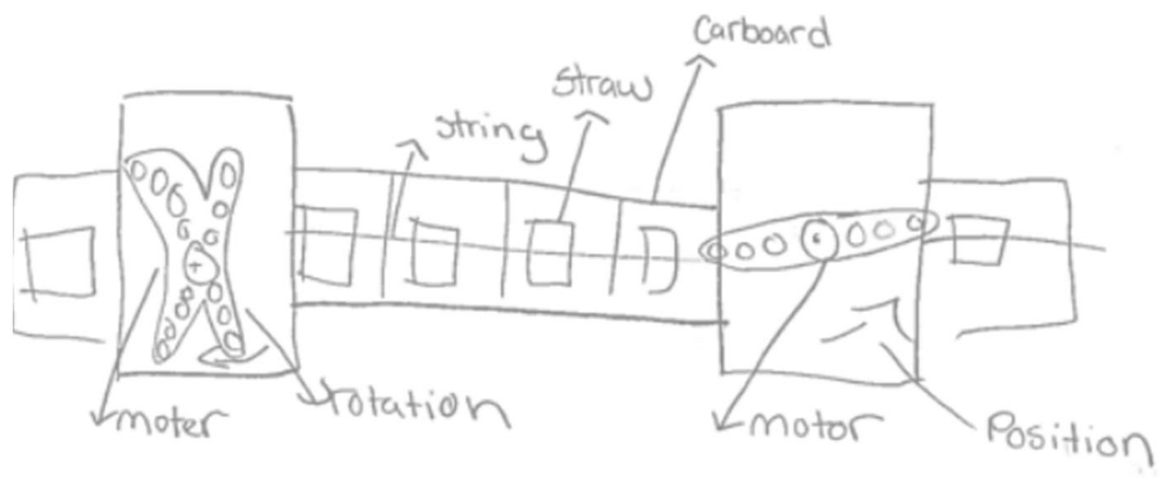

Fig. 5 Design sketch of a cable-drive mechanism for the robot's digging hand. CTERC 2021

goals, these students were able to identify a goal for their robot-to dig with a motion similar to the pangolin - and sketch out a proposed solution.

While the group was initially pleased with their design, the cable drive mechanism, once built, did not work as well as they had hoped. The string from the cable drive mechanism got caught on the motor, and they generally found that the cardboard hand was not sturdy enough to hold its shape and needed to be stronger if it was going to successfully dig. In their next iteration of the hand the team eliminated the cable-drive mechanism, added sturdier materials to the hand (popsicle sticks, metal fasteners), and added claws to enhance digging. The hand was built at a fixed angle so that it could 'scoop' up debris. As one of the students described in their interview, "if it was flat, it would just hit the dirt and it wouldn't really dig. And if it was bent, then it could pierce through the dirt and then, yeah, and then scoop it up." In addition, field notes documented the team's decision to add a second arm to their robot, because "then it will be a better replica of the real animal because it will have two arms instead of one." The group reported testing out their robot in a bin of shredded paper (provided by the teacher) "more than 20 times." During one of these tests field notes documented a conversation between the students and a classroom observer, where the students explained that the robot, "scoops like the pangolin" and that their next change would be to, "change the arm to make it more like hook and pull" (a reference to the 'hook and pull' style of 

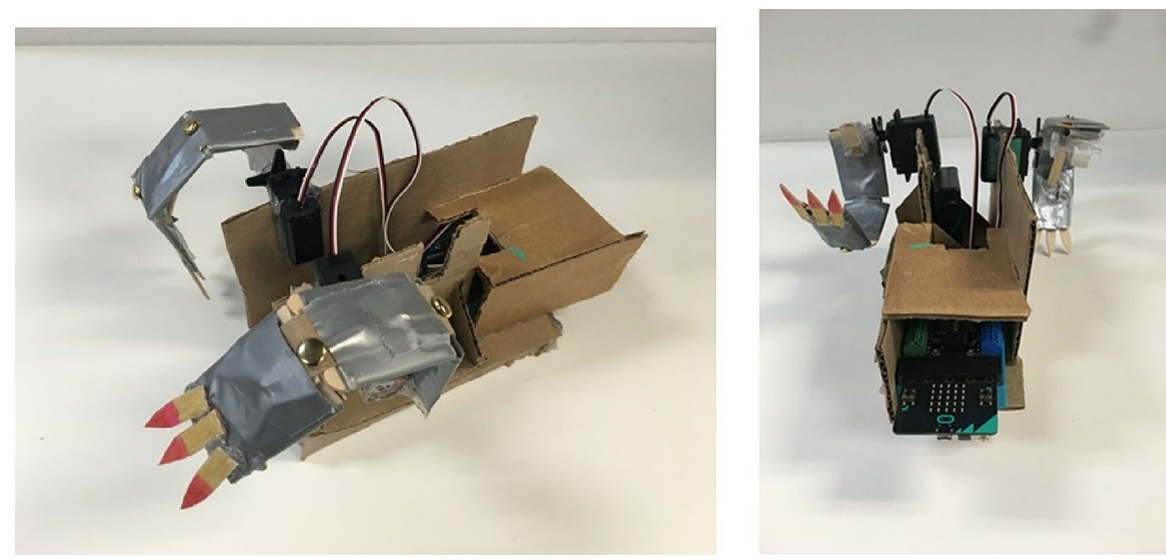

Fig. 6 Side (left) and back view (right) of a robot inspired by a pangolin. The robot has two motors mounted back-to-back. The claws rotate in a complete circle. CTERC 2021

digging that a pangolin uses). The group's efforts to identify design problems and test out iterative solutions was also consistent with the curriculum's learning goals.

The final robot was programmed to make the two robot hands spin in coordinated circles to help with digging (Fig. 6). Coordinating the motors so that that the hands spun at the same speed took time. As one student recalled, "one [arm] was going really fast, and so we slowed that one down and speeded the other one up until... we found like, like a ratio of this and this."

\section{Computational thinking goals}

Both in their biology investigations and during engineering design, students engaged in CT practices such as decomposition and abstraction. For example, their analysis of the structures and functions that their target animal used for digging constituted decomposition, and their illustration of these in their storyboard was an abstraction of that understanding. Likewise, in students' sketch of their proposed robot mechanism they identified the key features (abstraction) that they envisioned would effect the digging represented in the storyboard. Students also engaged in algorithm design as they sought to coordinate the movement of two motors.

\section{Next steps}

The Y2 curriculum supported students to enact CT practices (decomposition and abstraction), and to prioritize biomimetic design choices. It was our hope that by highlighting internal anatomy more clearly, students could notice that digging mechanisms are generally adapted to withstand digging forces (i.e., stout bones, muscles), and think more precisely about choosing stronger materials or forming materials into stronger 3D shapes.

The Y2 curriculum supported the design of robots that some students themselves described as mostly biomimetic in structure and function. However, the design team felt that the supports for animal analysis could be improved. The Y3 curriculum was designed to further strengthen the depth of students' understanding in biology, and use of ED and CT practices. It was designed to support students' efforts in translating 
from animal to robot by (1) directing students to examine both external and internal features that help animals dig and note planes of movement by drawing vector arrows, (2) directing students to return to the animal resources at some point during building for additional bio-inspiration and (3) providing additional tools for teachers to facilitate class-wide conversations about comparative anatomy so as to draw student attention to digging adaptations and relate these explicitly to robot designs.

\section{Year 3}

As in Y2, each of the focal groups completed an animal structure-function analysis, and designed a robot based upon one of four digging animals. The focal group we highlight here made maximal use of the additional supports, for example, returning to the animal resources repeatedly.

\section{Identifying a design goal}

As in Y2, the design goal, to build a robot that could dig through rubble at a disaster site, was provided. The group's animal inspirations were a pangolin and mole.

\section{Biology goal: understanding the structure-function relationship}

Students initially used curriculum resources to learn about the pangolin and sketched a detailed composite that included bones and muscles. Later they became interested in the mole following a peer group's presentation about the animal and conducted a detailed analysis of that organism's internal structure and type of motion. Their animal analysis highlighted skeletal and musculature structures that helped the animal dig (decomposition):

\footnotetext{
"You know, the way its arms are out, the way that it has all these parallel bits [the radius and ulna in the forearm] in its arm, you know, the way it has this whole extra bone coming down here, you know, all that stuff... Like the mole has, it has a very weird sort of shoulders. So it's got like this bone, like right where this would be, and then it has this gigantic bone [the scapula] that comes out like this. You know, so it has a lot, like it like pretty much gets rid of its shoulders to have that ex-, like it kind of gets rid of that to have that extra motion" [student interview].
}

In the group's storyboard, note how the students described the underlying digging mechanism in terms of skeletal movement, including how the animal pulls its shoulder blade (\#1 in Fig. 7) back causing the upper arm (\#4) to hinge relative to the skeleton. This pulls the hands and claws (\#6) back while the forearm bones (\#2 and \#3) keep the hands parallel. Consistent with the Y3 emphasis on internal skeletal structure and labeling movement, this storyboard provided additional anatomical detail of the animal including detail about the limb's functional connection to the body. In alignment with the Y3 learning goals this group identified both structures and functions that help the mole dig, and articulated how the position and movement of different structures contributes to digging. 


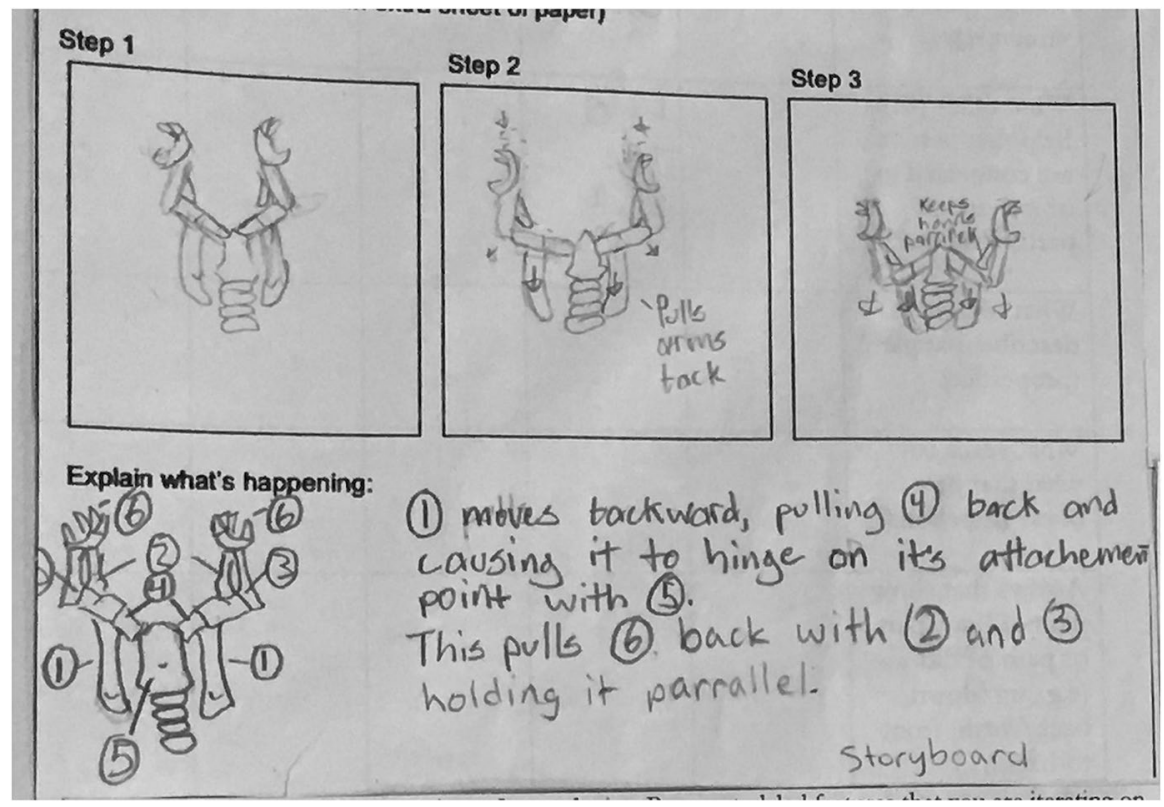

Fig. 7 Storyboard of the mole's skeletal structure to support digging. CTERC 2021

\section{Engineering design goals: enacting the engineering design process}

The group's early design sketch (Fig. 8, top) showed a rotating mechanism anchored by a fulcrum, designed to mimic a circular digging motion. Arrows indicated the intended plane of the robot's motion. In the final sketch (Fig. 8, bottom) the digging mechanism was shown in the context of the entire robot. In addition, the abstraction from animal to robot was shown by the label "hands" on the final robot. This final design sketch fairly accurately represented their final design.

Iterations on the robot design were intended to move the robot closer to the mole in both structure and function. The popsicle stick design of the robot's appendage (Fig. 9) was meant to reflect the parallelism in bone structure that students noted in the mole's forearm, while the overall motion of the robot reflected the mole's 'swimming' motion. In their interviews and design documentation, students described changes to the mechanical structure of the robot, and reported returning to images of the mole skeleton and to the video several times to refine their design. Students also reported making iterative changes to the materials used in the robot (e.g., doubling the popsicle sticks to make the robot stronger) and to programming (to try to ensure the appendages were moving simultaneously). In creating their design, these students prioritized parts and actions that mimicked the mole's method of digging. Their final design, which was well documented, encapsulated these efforts.

\section{Computational thinking goals}

As a result of our curricular refinements students were able to enact several CT practices more effectively. For example, they noticed and included more detail in their 

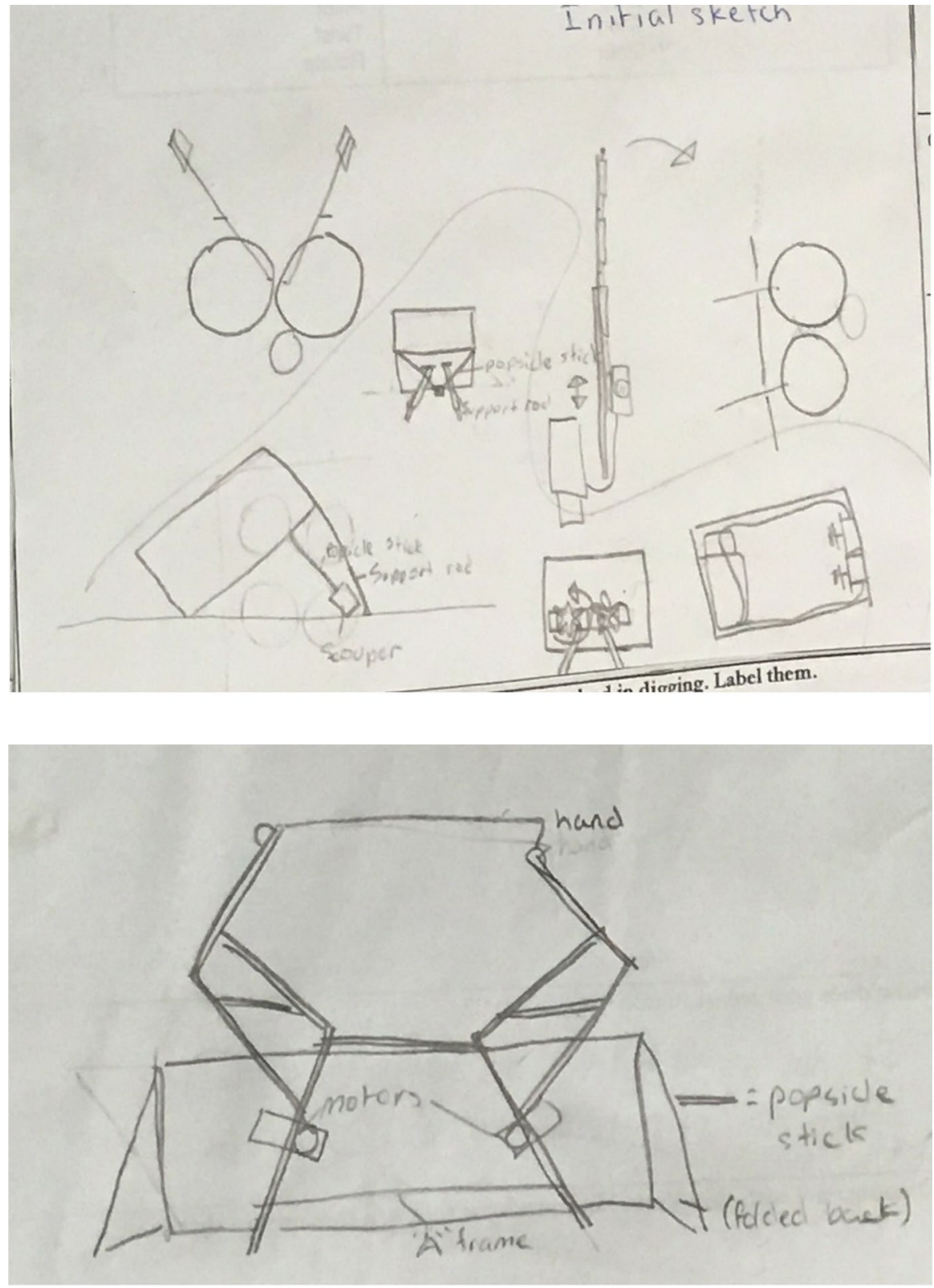

Fig. 8 Initial design sketch (top) and final sketch (bottom) of the robot. OTERC 2021

representations as a result of decomposition (Fig. 7). Not only did they draw the end effector (hand), students also noted its attachment to the body and its orientation, both of which were essential for the functioning of the robot they designed. 


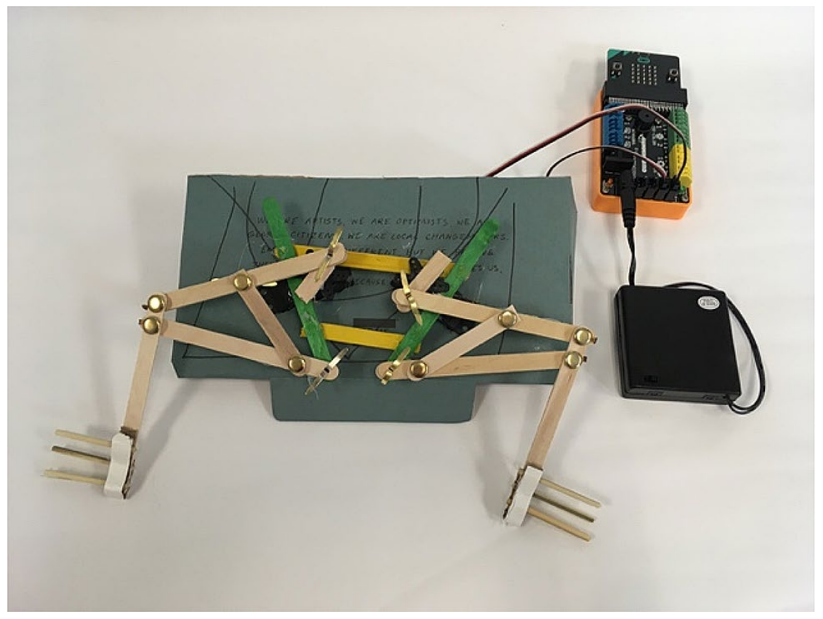

Fig. 9 Final robot design. CTERC 2021

In addition, the following excerpt illustrates their application of abstraction in the context of engineering. They talked in their interview about the degree to which their design represented the structure and function of the mole, the organism they were representing:

Student 1: Well, what really was interesting is, the video [curriculum resource] itself showed the fast movement through the soil, and the presenter [a member of another group], she showed the movement that worked with that, like swimming motion.

Student 2: ... you could see how its bones moved as it dug...

Student 1: So, but with the speed and the simple motion, we thought it would be the most effective way to dig, because of how it like, we thought we could actually, we thought the motion that we could create was a lot simpler than it actually was. And then we went to build it and it wasn't actually that simple.

Student 2: And then had to over-engineer the design.

As this excerpt explains, students' decomposition of mole movement allowed them to describe how the movement of the bones supported a swimming motion. They sought to capture this mechanism in their design (Fig. 8), but realized that an exact replication "wasn't actually that simple." Instead, while their abstracted design mimicked the mole's movement, the design difficulty necessitated the use of a different structure to achieve their movement (Fig. 9).

\section{Summary of how student data informed our design process}

This DBR study sought to understand how a technology design task could support student participation in practices related to biology, engineering, and CT. Across 3 years, we collected data to address specific questions about the scope of the design task, and about the extent to which supporting science and engineering practices helps students engage in discipline-driven design. Our conclusions about each question are summarized below. Additionally, Table 4 provides an overview of student participation in the technology design task during each year. 


\section{Scope of the design task (Y1)}

During Y1, the intended goal of helping students learn about animal structures and functions was not met. Focal group students examined a cockroach's behavior, but did not consider the details of how its body structure enabled that behavior, for example, how hinged joints allowed legs to bend. Perhaps as a result, the group needed help focusing their robot design efforts, which their teacher provided by suggesting they focus on an accordion motion for their robot (similar to the motion of an actual compressed cockroach) and helping them choose a mechanism for the design of the robot's legs that, while completely different from the structure of a cockroach leg, was an effective engineering solution that could result in a flattened cockroach. This data led us to conclude that a more constrained design task, supported by targeted (biology and engineering) structure-function resources, would better enable students to engage in disciplinedriven technology design.

\section{Supporting science, engineering and $\mathrm{CT}$ practices ( $\mathrm{Y} 2$ and $\mathrm{Y} 3$ )}

During Y2, the curriculum supported students to enact two key CT practices-decomposing the animal system (by identifying and documenting specific body parts that help the animal dig), and abstracting the functions most important for digging into their robot design. Students consistently prioritized parts and actions on the robot that would maximize its digging motion while trying to remain true to what they perceived as important parts of the animal's form (e.g., the pangolin's curved claws, adding a second limb to make their robot more similar to the animal). However, we noticed that students in Year 2 were not always extending their animal structure-function understanding to the choice or use of building materials. Students were relying on pliable materials (e.g., cardboard used only in flat pieces) instead of recognizing that digging structures needed to be stronger (e.g., cardboard shaped to be more resistant to bending, or reinforced with other materials). This led to an increased focus on animal internal anatomy, that is, a "deeper" process of decomposition, and other supports to help students, through the CT practice of abstraction, to draw analogies between animal and robot structures and functions (Cuperman \& Verner, 2019).

Using the revised Y3 version of the curriculum, students were able to conduct a more in-depth animal structure-function analysis and this helped guide their robot design. In Y1 and Y2, students had more difficulty translating their understanding of animal structure and function into robot designs. The Y3 focal group was able to mimic parts of the mole's anatomical structure and 'swimming' behavior in their final robot. We believe that the additional focus on internal and external animal structure resulted in a robot that mimicked both animals structure and function because decomposition and abstraction of both external and internal animal structure was so thoroughly accomplished.

\section{Discussion}

Our work surfaces many of the challenges that arise when designing an integrated STEM curriculum to support student use of multiple disciplines to solve a technology design task. Our DBR approach allowed us to test our empirical predictions and 


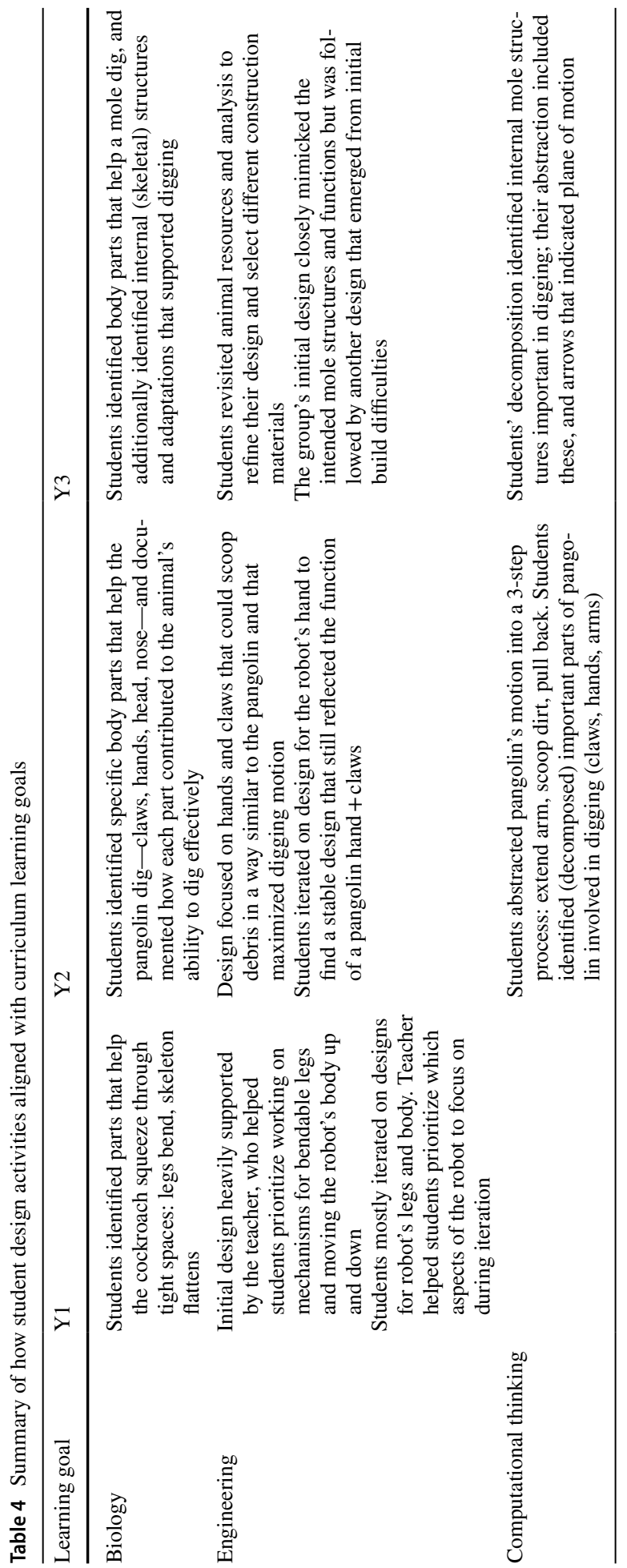


refine our design perspectives (Sandoval, 2014) during the cycles of implementation and redesign. In this section, we reflect on implications for design and for learning and offer suggestions for addressing these challenges.

\section{Design}

As Barber (2015) suggests, our design for integrated learning required continuous effort towards building on the synergies of the constituent disciplines and supporting the learning goals in each. Our data show that in the first year, students had mixed success in designing working biomimetic robots. In particular the open-ended nature of the design challenge, together with lack of sufficient supports for translating from biological structure-function to technology, meant that students examined animal digging functions but did not fully address the learning goal of understanding the relationship between animal structure and function. The year 2 iteration addressed this with a more explicit focus on analyzing structure-function relationships, and translation to robot mechanism, while reducing the emphasis on engineering design practices. The CT learning goals for decomposition and abstraction in Year 2 were also added. As a result, students were able to prioritize parts and actions on the robot that maximized digging function while mimicking the animal more closely. However, students did not extend their insights into animal structure to help them choose building materials. In year 3, curricular refinements supported students to mimic both structure and function because they were able to use the additional supports to decompose both external and internal animal structure so thoroughly.

The analysis of our design process and of student outcomes described in this paper result in two insights about design for integration, one of the desired outcomes from a DBR approach (Edelson, 2002). First, although there were some natural alignments between disciplines, those alignments needed to be carefully drawn out and prioritized, as Barber previously noted (2015), in order to afford students the opportunity to fully engage with integrated learning within the time constraints available. We did this by examining every possible practice represented by each activity in the curriculum to look for overlap, and prioritized activities that allowed us to draw out the natural synergies among them. For example, the recognition that there was alignment between analyzing animal structure-function and analyzing the corresponding robot structure-function as a CT practice-decomposition-meant that we could emphasize these activities and omit others, for example, the use of decision matrices for choosing design criteria, and still achieve the learning goals we had for the curriculum. Reducing the emphasis on engineering design practices reduced the time to complete the curriculum, one of the challenges that Kirshner (2015) notes is common for teachers when trying to implement integrated curricula.

Our second insight was the importance of being explicit about our design thinking in the teacher guide itself, thus providing additional context for recommended instructional strategies (Pareja-Roblin et al., 2018). Accordingly, we called out the triple focus on biology, and on engineering and CT practices in each module, and provided examples of student work to illustrate the purpose of each activity and how it could support student progress. This reflects Chiu and Linn's (2011) observation that explicitly emphasizing connections among ideas from different sources help students connect across disciplines. 


\section{Learning}

We believe this work demonstrates how a robotic design task can support student learning across disciplines. The analysis of student outcomes described in this paper results in another desired outcome of the DBR approach, a contribution to theory development in understanding better the conditions for bringing about learning outcomes in this learning environment (Easterday et al., 2014; McKenney \& Reeves, 2019; Sandoval, 2014). As others have argued, design work is a good vehicle for promoting disciplinary learning (Kolodner et al., 2003; Mehalik et al., 2008), and robotics design in particular provides students with opportunities to practice computational thinking skills (Sullivan \& Heffernan, 2016).

As the scope, sequence, and curricular resources evolved and the disciplinary alignment sharpened, we saw a change in students' ability to engage in integrated disciplinary work. During Y1, students needed help from their teacher to prioritize and execute their design and building efforts. It was the teacher who helped the Scoutroach group prioritize certain actions for the robot and then encouraged them to focus on mechanisms for compressing the robot's legs and body. In contrast, by Y3, the deep animal analysis work completed by students guided their robot design process and final product (Shaw et al., 2020), enabling students to move from animal investigations to their initial robot design more independently and ensuring that their design iterations maintained a focus on mimicking animal structures and functions.

These data suggest that integrating CT in both biology and engineering and providing explicit support for these enabled students to bridge between the disciplines. This reflects research reported by Aksit and Wiebe (2019) and (Puttick \& Tucker-Raymond, 2018), that embedded CT practices can actively enhance disciplinary learning. The focus on decomposition and abstraction both deepened students' biology investigations and facilitated a more targeted robotics design process that drew on animal structures and functions. We saw additional examples of this bridging work in the language students used to describe their robots, for example labeling parts of the robot as "claws" in reference to the animal structures that inspired their design.

\section{Conclusion}

We began our DBR study focused on the design challenge of creating a fully integrated curriculum in which no one discipline dominated. We looked to the extent to which student artifacts displayed evidence of integrated learning to guide our revisions both of "substantive specifications" in the curriculum-for example, modifying curricular materials and the learning goals themselves - and "procedural specifications" (McKenney \& Reeves, 2019), for example, modifying recommended sequences for student use of particular project resources.

Our study showed that explicit and targeted curricular supports, prioritizing specific science, CT, and engineering practices, chosen for their natural synergies among the disciplines (Barber, 2015), specifying how students should engage with the practices in the context of the technology design task, were necessary to support integrated learning. We believe the implications of our findings are relevant for the design of integrated curriculum. Future research could address how teachers take up and enact these challenging curricula 
and how student learning is supported by the careful design of resources and representations across disciplines.

\section{Limitations}

A challenge for design-based research is the extent to which results can be generalized. The principles derived from our work may only be relevant to designs for parallel contexts and similar settings (Wang \& Hannafin, 2005). Our results may not apply to other learning contexts focused on the implementation of curricula that integrate disciplines other than biology, engineering/robotics and CT. As with any DBR study, readers must extrapolate generalizations to their own context in ways they see fit. Finally, the curriculum design research team conducted data collection and data analysis, and our influence may inadvertently have affected research outcomes.

Acknowledgements The authors sincerely thank the teachers and students involved in the Designing Biomimetic Robots project for their participation and contributions. Earlier versions of this work were presented at the American Educational Research Association (AERA) and International Society for Technology in Education (ISTE) conferences. This material is based upon work supported by the National Science Foundation under Grant Number 1742127. Any opinions, findings, and conclusions or recommendations expressed in this material are those of the author(s) and do not necessarily reflect the views of the National Science Foundation.

Funding This study was funded by the National Science Foundation (Award \#1742127).

\section{Declarations}

Conflict of interest The authors declare that they have no conflict of interest.

Ethical approval Approval for this study was obtained by the Institutional Review Board at TERC.

Informed consent Informed consent was obtained from participants in the study.

Open Access This article is licensed under a Creative Commons Attribution 4.0 International License, which permits use, sharing, adaptation, distribution and reproduction in any medium or format, as long as you give appropriate credit to the original author(s) and the source, provide a link to the Creative Commons licence, and indicate if changes were made. The images or other third party material in this article are included in the article's Creative Commons licence, unless indicated otherwise in a credit line to the material. If material is not included in the article's Creative Commons licence and your intended use is not permitted by statutory regulation or exceeds the permitted use, you will need to obtain permission directly from the copyright holder. To view a copy of this licence, visit http://creativecommons.org/licenses/by/4.0/.

\section{References}

Aksit, O., \& Wiebe, E. N. (2019). Exploring force and motion concepts in middle grades using conceptual modeling: A classroom intervention study. Journal of Science Education and Technology, 29, 65-82.

Anwar, S., Bascou, N. A., Menekse, M., \& Kardgar, A. (2019). A systematic review of studies on educational robotics. Journal of Pre-College Engineering Education Research (J-PEER), 9(2), 2.

Applebee, A. N., Adler, M., \& Flihan, S. (2007). Interdisciplinary curricula in middle and high school classrooms: Case studies of approaches to curriculum and instruction. American Educaitonal Research Journal, 44(4), 1002-1039. 
Atmatzidou, S., \& Demetriadis, S. (2016). Advancing students' computational thinking skills through educational robotics: A study on age and gender relevant differences. Robotics and Autonomous Systems, $75,661-670$

Barber, J. (2015). How to design for breakthrough: A story of collaborative design across disciplines. Educational Designer, 2(8). Retrieved from http://www.educationaldesigner.org/ed/volume2/issue8/artic le29/

Barker, B. S., \& Ansorge, J. (2007). Robotics as a means to increase achievement scores in an informal learning environment. Journal of Research on Technology in Education, 39(3), 229-243.

Becker, K., \& Park, K. (2011). Effects of integrative approaches among science, technology, engineering, and mathematics (STEM) subjects on students' learning: A preliminary meta-analysis. Journal of STEM Education: Innovations and Research, 12(5/6), 23-37.

Benitti, F. (2012). Exploring the educational potential of robotics in schools: A systematic review. Computers \& Education, 58, 978-988.

Bers, M. U., Flannery, L., Kazakoff, E. R., \& Sullivan, A. (2014). Computational thinking and tinkering: Exploration of an early childhood robotics curriculum. Computers \& Education, 72, 145-157.

Brennan, K., \& Resnick, M. (2012). New frameworks for studying and assessing the development of computational thinking. Paper presented at the International Conference of the American Educational Research Association, Vancouver, BC, Canada.

Buckley, B. C. (2000). Interactive multimedia and model-based learning in biology. International Journal of Science Education, 22(9), 895-935.

Cejka, E., Rogers, C., \& Portsmore, M. (2006). Kindergarten robotics: Using robotics to motivate math, science, and engineering literacy in elementary school. International Journal of Engineering Education, $22(4), 711$.

Chiu, J. L., \& Linn, M. C. (2011). Knowledge integration and wise engineering. Journal of Pre-College Engineering Education Research (J-PEER), 1(1), 1-14.

Clement, J. J., \& Rea-Ramirez, M. A. (Eds.). (2008). Model based learning and instruction in science. Springer.

Cobb, P., Confrey, J., diSessa, A., Lehrer, R., \& Schauble, L. (2003). Design experiments in educational research. Educational Researcher, 32(1), 9-13.

Collins, A., Joseph, D., \& Bielaczyc, K. (2004). Design research: Theoretical and methodological issues. Journal of the Learning Sciences, 13(1), 15-42.

Corbin, J., \& Strauss, A. (2015). Basics of qualitative research. Sage.

Cuperman, D., \& Verner, I. M. (2013). Learning through creating robotic models of biological systems. International Journal of Technology and Design Education, 23(4), 849-866.

Cuperman, D., \& Verner, I. M. (2019). Fostering analogical reasoning through creating robotic models of biological systems. Journal of Science Education and Technology, 28, 90-103.

Easterday, M.W., Lewis, D.R. \& Gerber, E. (2014). Design-based research process: Problems, phases and applications. Proceedings of the 2014 ICLS, 317-324.

Edelson, D. C. (2002). Design research: What we learn when we engage in design. Journal of the Learning Sciences., 11(1), 105-122.

English, L. D. (2016). STEM education in K-12: Perspectives on integration. International Journal of STEM Education. https://doi.org/10.1186/s40594-016-0036-1

English, L., \& Mousoulides, N. (2015). Bridging STEM in a real-world problem. Mathematics Teaching in the Middle School, 20(9), 532-539.

Gomez, K., Bernstein, D., Zywica, J., \& Hamner, E. (2012). Building technical knowledge and engagement in robotics: An examination of two out-of-school programs. In B. Barker, G. Nugent, N. Grandgenett, \& V. I. Adamchuk (Eds.), Robotics in K-12 education: A new technology for learning (pp. 222-244). IGI global.

Grover, S., \& Pea, R. (2013). Computational thinking in K-12: A review of the state of the field. Educational Researcher, 42(1), 38-43.

Hamner, E., Zito, L., Cross, J., Slezak, B., Mellon, S., Harapko, H., \& Welter, M. (2016, October). Utilizing engineering to teach non-technical disciplines: case studies of robotics within middle school English and health classes. In: 2016 IEEE Frontiers in Education Conference (FIE) (pp. 1-9). IEEE.

Huntley, M. (1998). Design and implementation of a framework for defining integrated mathematics and science education. School Science and Mathematics, 98(6), 320-327.

Hurley, M. M. (2001). Reviewing integrated science and mathematics: The search for evidence and definitions from new perspectives. School Science and Mathematics, 101(5), 259-268.

Kirschner, P. (2015). Do we need teachers as designers of technology enhanced learning? Instructional Science, 43, 309-322. 
Kolodner, J. L., Camp, P. J., Crismond, D., Fasse, B., Gray, J., Holbrook, J., et al. (2003). Problem-based learning meets case-based reasoning in the middle-school science classroom: Putting learning by design into practice. Journal of the Learning Sciences, 12(4), 495-547.

Lee, I., \& Malyn-Smith, J. (2020). Computational thinking integration patterns along the framework defining computational thinking from a disciplinary perspective. Journal of Science Education and Technology, 29, 9-18.

Margot, K. C., \& Kettler, T. (2019). Teachers' perception of STEM integration and education: A systematic literature review. International Journal of STEM Education. https://doi.org/10.1186/ s40594-018-0151-2

McKenney, S., \& Reeves, T. C. (2019). Conducting educational design research (2nd ed.). Routledge.

Mehalik, M. M., Doppelt, Y., \& Schunn, C. D. (2008). Middle-school science through design-based learning versus scripted inquiry: Better overall science concept learning and equity gap reduction. Journal of Engineering Education, 97(1), 71-85.

Michelsen, C., \& Sriraman, B. (2009). Does interdisciplinary instruction raise students' interest in mathematics and the subjects of the natural sciences? Mathematics Education, 41(1), 231-244.

Mitnik, R., Nussbaum, M., \& Recabarren, M. (2009). Developing cognition with collaborative robotic activities. Educational Technology \& Society, 12(4), 317-330.

Nadelson, L. S., \& Seifert, A. L. (2017). Integrated STEM defined: Contexts, challenges, and the future. The Journal of Educational Research, 110(3), 221-223. https://doi.org/10.1080/00220671.2017.1289775

Nathan, M. J., Srisurichan, R., Walkington, C., Wolfgram, M., Williams, C., \& Alibali, M. W. (2013). Building cohesion across representations: A mechanism for STEM integration. Journal of Engineering Education, 102(1), 77-116.

National Academy of Engineering and National Research Council. (2014). STEM integration in K-12 education: Status, prospects, and an agenda for research. National Academies Press.

Nourbakhsh, I., Crowley, K., Bhave, A., Hamner, E., Hsiu, T., Perez-Bergquist, A., et al. (2005). The robot autonomy mobile robotics course: Robot design, curriculum design and educational assessment. Autonomous Robotics Journal, 18(1), 1-25.

Nugent, G., Barker, B.S., Grandgenett, N., \& Adamchuk, V.I. (2010). Impact of robotics and geospatial technology interventions on youth STEM learning and attitudes. Teacher Education Faculty Publications. Paper 33. Retrieved from http://digitalcommons.unomaha.edu/tedfacpub/33

Pareja-Roblin, N., Schunn, C., \& McKenney, S. (2018). What are critical features of science curriculum materials that impact student and teacher outcomes? Science Education, 102(2), 260-282.

Puttick, G., \& Tucker-Raymond, E. (2018). Building systems from scratch: An exploratory study of students learning about climate change. Journal of Science Education and Technology, 27(4), 306-321.

Saez-Lopez, J., Sevillano-Garcia, M., \& Vazquez-Cano, E. (2019). The effect of programing on primary school students' mathematical and scientific understanding: Educational use of mBot. Education Technology Research \& Development, 67, 1405-1425.

Sandoval, W. (2014). Conjecture mapping: An approach to systematic educational design research. Journal of the Learning Sciences, 23(1), 18-36.

Shaw, F., Kshirsagar, K., Wendell, K., Danahy, E., Bernstein, D., Puttick, G., \& Cassidy, M. (2020, October). Characterizing student artifacts in a multi-disciplinary biomimicry and robotics unit [Conference presentation]. FabLearn Conference (Virtual).

Shaw, F., Wendell, K., Puttick, G., Bernstein, D., \& Danahy, E. (2018). Problem scoping in designing biomimetic robots. In J. Kay \& R. Luckin (Eds.), Rethinking learning in the digital age: Making the learning sciences count, 13th international conference of the learning sciences (ICLS) 2018. (Vol. 3). International Society of the Learning Sciences.

Souza, M. A., \& Duarte, J. R. (2015). Low-cost educational robotics applied to physics teaching in Brazil. Physics Education, 50(4), 482.

Stoddart, T., Pinal, A., Latzke, M., \& Canady, D. (2002). Integrating inquiry science and language development for English language learners. Journal of Research in Science Teaching, 39(8), 664-687.

Sullivan, F. (2008). Robotics and science literacy: Thinking skills, science process skills and systems understanding. Journal of Research in Science Teaching, 45(3), 373-394.

Sullivan, F. R., \& Heffernan, J. (2016). Robotic construction kits as computational manipulatives for learning in the STEM disciplines. Journal of Research on Technology in Education, 48(2), 105-128.

Tucker-Raymond, E., Varelas, M., \& Pappas, C. C. (2013). Conceptions of Being Scientists. In M. Varelas \& C. C. Pappas (Eds.), Children's Ways with Science and Literacy: Integrated Multimodal Enactments in Urban Elementary Classrooms (pp. 186-209). Routledge.

Walker, W. S., Moore, T. J., Guzey, S. S., \& Sorge, B. H. (2018). Frameworks to develop integrated STEM Curricula. K-12 STEM Education, 4(2), 331-339. 
Wang, F., \& Hannafin, M. J. (2005). Design-based research and technology-enhanced learning environments. Educational Technology Research and Development, 53, 5-23.

Waterman, K. P., Goldsmith, L., \& Pasquale, M. (2020). Integrating computational thinking into elementary curriculum: An examination of activities that support students' computational thinking in the service of disciplinary learning. Journal of Science Education and Technology, 29, 53-64.

Welch, A., \& Huffman, D. (2010). The effect of robotics competitions on high school students' attitudes toward science. School Science and Mathematics, 111(8), 416-424.

Wendell, K. B., \& Kolodner, J. (2014). Learning disciplinary concepts and practices through Engineering design. In B. Olds \& A. Johri (Eds.), Cambridge handbook of engineering education research. Cambridge University Press.

Wendell, K. B., \& Rogers, C. (2013). Engineering design-based science, science content performance, and science attitudes in elementary school. Journal of Engineering Education, 102(4), 513-540.

Wendell, K., Shaw, F., Kshirsagar, K., Danahy, E., Bernstein, D., Puttick, G., \& Cassidy, M. (2020). Navigating dual goals of team collaboration and design concept development in a middle school bio-inspired robotics unit. In M. Gresalfi \& I. S. Horn (Eds.), The interdisciplinarity of the learning sciences, 14th international conference of the learning sciences (ICLS) 2020 (Vol. 2, pp. 895-896). International Society of the Learning Sciences.

Yin, R. K. (2009). Case study research: Design and methods. Sage publications.

Publisher's Note Springer Nature remains neutral with regard to jurisdictional claims in published maps and institutional affiliations.

Debra Bernstein is a senior researcher in the STEM Education Evaluation Center (SEEC) at TERC, a nonprofit research and development organization. Her research interests include curriculum design, implementation, and learning opportunities arising from the integration of technology design activities into K-12 and informal learning settings.

Gillian Puttick a senior scientist at TERC, has directed many federally funded education research projects focused on life science. Using an inquiry-based philosophy, she has brought new scientific discoveries to formal and informal settings through designing and testing curriculum, programs and activities for students and teachers.

Kristen Wendell is an associate professor in mechanical engineering and education at Tufts University. Her research focuses on supporting productive and equitable classroom discourse in engineering learning experiences in K-12, undergraduate, and teacher education contexts.

Fayette Shaw received her $\mathrm{PhD}$ from the University of Washington and is currently a postdoctoral scholar at the Center for Engineering Education and Outreach (CEEO) with interests in makerspaces, e-textiles, and women in STEM. Prior to joining the CEEO, she was a Product Design Engineer in the Softgoods group at Apple.

Ethan Danahy is a Research Assistant Professor at the Center for Engineering Education and Outreach (CEEO) with secondary appointment in the Department of Computer Science within the School of Engineering at Tufts University. His research focuses on the design, implementation, and evaluation of different educational technologies, ranging from software and hardware to interfaces and environments.

Michael Cassidy Ph.D., is a Senior Researcher at TERC. His work focuses on teacher professional learning, computational thinking, engineering education, robotics, and evaluation of mathematics and science intervention programs. 